\title{
Analysis on the Personality of Maggie by Jung's Archetype Theory
}

\author{
Jiang Zhu \\ School of Foreign Languages, Changchun University of Science and Technology, Changchun 130022, China \\ Lemeng Han \\ Department of Common Foreign Language Teaching, Guanghua College of Changchun University, Changchun, China
}

\begin{abstract}
Maggie is the heroine of Stephen Crane's novel Maggie: A Girl of the Street. This paper analyzes the personality of Maggie according to Jung's archetype theory and comes to the conclusion that the deficiency on Maggie's personality is a main reason for her tragedy.
\end{abstract}

Index Terms - archetype, persona, shadow, anima, animus

\section{INTRODUCTION}

Stephen Crane is the forerunner of American naturalism. His work Maggie: A Girl of the Street is the first American naturalistic novel. In this novel Crane portrayed the dreadful life of an innocent girl, Maggie, who lived in a slum of New York. Maggie was seduced by the bartender Pete and was discarded. Maggie's family showed no sympathy to her and did not allow her to return home. Maggie had to live as a whore and committed suicide at last (Stephen, 1986). This paper will analyze Maggie's personality based on Jung's archetype theory and summarize the reasons of Maggie's tragedy.

\section{THE ARChETYPES OF CARL GUSTAV Jung}

According to Jung, archetypes are innate universal psychic dispositions that form the substrate from which the basic symbols or representations of unconscious experience emerge. According to Jung's study, there are four types of universal archetypes: Mother, Rebirth, Spirit, and Trickster or Devil. "The archetype is a trend which could form some representations of motif (Jung, 2003). Representations can be various in details without losing their basic pattern. They are indeed an instinctive trend". The motifs are nothing more than conscious representations. Contrary to the deeper and instinctive sources such as the archaic remnants which can be called as "archetypes" or "primordial images", it would be absurd to assume that such variable representations could be inherited. Jung also described some typical archetypal events: birth, death, separation from parents, initiation, marriage, etc. Some archetypal figures could be mentioned as great mother, father, child, hero, etc. The archetype of initiation is strongly activated to provide a meaningful transition, with a "rite of passage" from one stage of life to the next. Such stages may include being parented, initiation, courtship, marriage and preparation for death.

Although the general idea of archetype is well recognized, there is considerable confusion to its exact nature and the way of how they lead to universal experiences. The confusion about the archetypes can partly be attributed to Jung's own evolving ideas about them in his writings and his interchangeable use of the term "archetype" and "primordial image". It may also be attributed to the fact that, given his belief that "archetypal symbols are spontaneous products of the unconsciousness", Jung was always intended "not to weaken the specific individual and cultural values of archetypes by leveling them out, for example, by giving them a stereotyped, intellectually formulated meaning".

Strictly speaking, archetypal figures such as the hero, the goddess and the wise man are not archetypes, but archetypal images which have crystallized out of the archetypes, as Jung put it, "definite mythological images or the archetype of order". Although the number of archetypes is limitless, there are a few particularly notable, and recurring archetypal images. The chief images are "the shadow, the wise old man, the child including the child hero, the mother and her counterpart, the maiden, and lastly the anima in man and the animus in woman".

The content of the archetypes is the collective unconsciousness of human beings. It also means the primary pattern, so all the similar matters imitate this pattern. It is the synonym of prototype. In order to understand the archetypes of Jung, a point is very important, that is, archetype is quite different from the memory image in your experience, and it is not a clear view in your mind. For example, the mother archetype does not account to the picture of the mother or some woman. It looks more like a film of your later experience. Some archetypes are very important in the formality of our personality and behavior. These archetypes are: the persona, anima and animus, and the shadow. Although archetype is a separated structure from collective unconsciousness, they can combine together under some certain circumstances. For example, if the hero archetype combines with evil archetype, maybe it forms a "brutal leader". If witchery archetype combines with birth archetype, the result would be the "birth witch" in the original culture. Since archetypes 
can interact in different formulation, it works as the factor to influence the diversity of personality. Archetype is a general concept, that is to say, everyone derives from the same basic archetype image. The babies all over the world naturally have mother archetype unconsciously, but this archetype will generally turn to a clear image through the behavior, appearance and contact with the real mother. Different relationship between mother and child in different families may result in different mother images. According to Jung, as the appearance of the races, the diversity of collective unconsciousness came into being.

\section{A. Persona}

To Jung, persona is a mere "functional complex ... by no means identical to the individuality", the way of how we present or face to the world. It is a mask which protects the ego from negative images and according to post-Jungians, it is sometimes considered as a dynamic or structural component of the psyche. According to Jung's writings, the original meaning of the word "persona" is a mask to make sure an actor could act well in a play (Jung, 2003). There are also two paronyms: "person" and "personality". Theoretically, the persona makes a person have a certain kind of personality, but this personality may not be his real personality. Persona is just a person's publicly displayed appearance, the purpose of which is to gain a social permission. It also has another name "conformity archetype". Only when the archetype is beneficial for the individual and the nationality can it be a person's instinctive nature. Persona is essential for a person's survival, and is basic for social and public life. It makes us get along well with the others even someone we dislike, and makes a person's aim come true. For example, if a young man wants to gain achievement in his company, he should first know what kind of role he should play in the company, and what he should pay attention including behavior, appearance, modesty, his policy, his car, his wife as well as some other factors which are important to the company. And of course, he should first be hard-working, reliable, active, but all these are just a part of persona. If a young man can not play his role well in the company, he will not get any promotion and even be fired. Everyone may have one different persona, at work, at home, or with friends. They could change their masks, and all these masks make his adaptation to different situations in different ways. People have seen this as a key condition, but before Jung, it is not mentioned. This adaptation is an instinctive archetype. Persona sometimes is beneficial, and sometimes harmful. If a person is too much addicted to the role he is playing, the other aspects of his personality would be excluded. He will stay in a very tense state because his strong persona is contradicted with his other weak sides in his personality. If a person confirms his persona too much, it is "inflation". He will be proud of what he is trying to be or act, and enforce this role to others. All the laws and customs actually are the display of collective persona. These laws and customs enforce some certain behavior patterns to the whole collective without the consideration of the need of the individual, which means that inflation of persona will do harm to people's psychological factors. On the other hand, the victims are also themselves for the inflation ones. If they could not get what they require, they would feel pessimistic and pitiful for themselves.

Jung has enough time and condition to make research on the bad effect of people with inflation for most of his patients are victims of inflation. All these patients are from high occupations, but they suddenly find that their lives are very empty and meaningless. Usually when they come to the middle age, they feel the crisis from the persona of inflation. The therapy of the patients is to restrain the persona of inflation, and free all the other personas, no matter good or bad. Therefore a way should be sought to keep balance among all the personas.

\section{B. Shadow}

Shadow refers to the opposite of the ego image, often containing qualities that the ego does not identify with but possesses nonetheless. Shadow contains human's animal features more than any other archetype, and it may be the strongest and most dangerous archetype for it has profound basis during the evolution of human beings. It is the origin of all the good and bad things which are usually shown in the relationship between the same sexes. Jung considered the shadow to be the undeveloped suppressed mental functions (usually one or two of them) which could be released in a period of extreme stress. If some functions are undeveloped, and have no form of sublimation, they are suppressed. Under great stress, the person may not be able to hold them anymore, so that the shadow gets out. This can be verified in the fact that the person acts according to opposite type. In this case neither was under great stress, at least not from the issues involved. What they have done has been pretty consistent in their behaviors towards those who disagree with them even if it was a minute point. However, this does not mean that there is no great stress in their lives in other areas and that it is manifested on the net due to the ability to be anonymous to many people. According to Jung, if it is not stress, it is not shadow. Then Jung said that stress is the obstacle. This seems a bit absurd. Stress can bring out the best in a person or the worst. Jung calls the shadow the undeveloped processes coming out uncontrolled. This only happens under stress, for the immature processes are either suppressed or controlled. Basically, the stress makes it harder and even impossible for the person to continue suppression. The shadow is too strong to be suppressed. The following example is a good explanation. A farmer might be called by inspiration to become a poet, but the farmer did not feel that the calling was sensible. Because his persona was very strong, he always rejected the voice from the heart. But the voice disturbed his mood constantly till one day he took up his pen. Shadow always adheres to certain ideas or imagination which can be eventually proved to be beneficial or harmful. When shadow cooperates with ego perfectly, human could feel dynamic, which is the time when ego does not stop but lead the vitality to release from the instinct, which makes the spiritual activities become rich and vigorous. So it is not strange that creative people whose shadow can suppress his 
ego at any time are always full of animal features and look strange.

\section{Anima and Animus}

Animus is the masculine image in a woman's psyche. Persona is a publicly displayed aspect. Jung called it as "outward face" of spirit, and he called anima of male and animus of female as "inward face". Anima is the female aspect of male, and animus is the male aspects of female, as every person may have opposite sex features. From the biological aspect, both male and female secrete masculine hormones and feminine hormones. From the psychological aspect, human's emotion has bisexual tends. For thousands of years, male has anima archetype by interacting with female, and female has animus archetype by interacting with male. This anti-sex keeps balance and understanding between male and female. Anima and Animus should be displayed in individual's consciousness and behavior. If a male only shows his masculine feature, his feminine feature will be hidden in his unconsciousness, which makes him weak and sensitive unconsciously. Therefore some masculine people in fact are very weak and tender in the inner heart. Every male has a permanent female spirit in the inner heart. This is not some certain female image, but a female spirit which is unconscious and carved in the male's body as an original genetic element. According to Jung, male naturally has female spirit, and he will set a kind of standard which will influence his option of female, and determine whether he likes or dislikes some girl. The first anima inflection is usually his mother, and the first inflection of animus is always the father. After that, anima archetype will be inflected to a woman, who could arouse his emotion. If the male feel a passionate attraction, the woman must have the same anima spirit with the male. Many people are the victims of personas. But anima and animus are quite different. The two archetypes can not get sufficient development, for in the culture, people usually focus on the consistence of the characters and discriminate the female features on the males or the male features on the females. Such discrimination begins at a person's childhood. People always hope that man is the traditional man and woman the traditional woman, so the persona occupies and constrains the anima and animus. The contradiction between persona and anima and animus would result in the revenge of anima and animus. Under such circumstances, human will go to another extreme.

\section{ThE ARChETYPE OF MAGGIE}

The persona of Maggie is beautiful and pure. Maggie is a kind girl. It is said that she is just like a flower in the mud. The shadow of Maggie is embodied in her behavior especially her unconscious impulse. Such kind of impulse made her love Pete for the first sight without noting that Pete was a playboy and had many affairs with a lot of women. Maggie loved him and believed that Pete was her ideal man, which was an important reason for her destiny (Fryer, 1976). The animus of Maggie could be seen in her courage to pursue love. In order to help the family, Maggie went out to work in a dreadful factory and had to endure the unfair treatment from the Boss. To pursue love was a relief of the pain she suffered in her work.

\section{A. The Influence of Persona on Maggie}

What should be mentioned again is that persona is the aspect that people display publicly in order to get an approval from the society, so it can also be called "conformity archetype". The function of persona in personality can be both beneficial and harmful. If a person excessively addicts to or accept the only role he plays, the other aspects of the personality will be excluded. The person who is controlled by persona will live in tension of conflict between the developed persona and undeveloped other aspects in personality. If an individual extremely conducts self-identity of persona, the circumstance is called "inflation" and the individual usually impose the role on others. The inflation of persona will do harm to the mental health (James, 1983). Maggie played the role of persona as a good girl. She was tender, demure, sensitive and innocent, but these characters were also the persona of weakness and made her conceited. She looked forward to the rich life of the upper class. After she met Pete the bartender, she reflected upon the collar-and-cuff factory. It began to appear in her mind as a dreary place of endless grinding. Pete's elegant occupation brought him, no doubt, into contact with people who had money and manners. It was probable that he had a large acquaintance with pretty girls. He must have great sums of money to spend. When she saw him twice and he wore a different suit each time, Maggie had a dim impression that his wardrobe was prodigious. To Maggie the world is full of hardship and insult, so her instant admiration for a man made her full of fantasy. When she saw him, her eyes dwelt wonderingly and rather wistfully upon Pete's face. She looked keenly at him, occasionally wondering if he was feeling contempt. She perceived that here was the ideal man. Her dim thoughts were often searching for faraway lands where the little hills sing together in the morning. Under the trees of her dream gardens there was always a lover. The love and admiration for Pete made him take good advantage. She identified herself as a good girl more than everything. This meant that her persona was very strong. Even when she was seduced by Pete, she still faced everything with her weakness. When she was forlorn, she came to Pete, but the bartender made a violent gesture of impatience and cried with an air of injury. When she came back to her family, she was refused and cursed by her mother and brother. It seemed that everyone around her duped her, and in the process of her pursuit of happiness, her weakness made her unable to fight against the fate thoroughly. When she was abandoned by everyone, she was in despair. She had no way to go and committed suicide. From this aspect, her weakness and kindness caused her tragedy.

\section{B. The Influence of Shadow on Maggie}


Shadow provides people with natural wisdom which is more profound than any knowledge or culture. Shadow usually involves some concept or image, which may be both beneficial and harmful to human beings. When shadow and ego cooperate with each other harmoniously, and ego does not stop but supervise the vitality to release from the instinct, shadow is characterized. Shadow contains the basic and normal instinct and it is the source of insight and reaction force. People may encounter some circumstances that need a rapid response when there is not enough time to analyze or consider the situation to respond appropriately. Under such circumstance, shadow or the unconsciousness will make reaction to the situation with a unique mode. If shadow has been characterized, it will react in a proper way. If shadow has been suffering from depression all the time, this instinctive catharsis will cause a person to be incapable of action. Simply speaking, to some extent shadow is the unconsciousness of a person. It is his heart, his impulse to do something.

For Maggie, it is believed that her sudden curiosity to Pete made her fall into the tragedy of death. The hardship and poverty of her life made Maggie have an instinct desire for a better life, so when she saw Pete, she could not hold her impulse to admire him, for her, his mannerisms stamped him as a man who had a correct sense of his personal superiority. There were valor and contempt for circumstances in the glance of his eye. He waved his hands like a man of his world who dismisses religion and philosophy. He had certainly seen everything, and with each curl of his lip he declared that it amounted to nothing. Maggie thought he must be a very "elegant" bartender. Her shadow, which was not individualized, made her unable to make a correct judgment on Pete. She did not realize that Pete was a playboy and had affaires with a lot of women. He was almost as obscene as a pimp. She took Pete's boasting as truth, and thought he was a formidable man who disdained the strength of the world. He was one who had contempt for brass-clothed power, one whose knuckles could ring defiantly against the granite of law. He was a knight.

Pete took her to see the show of orchestra. In fact it was a very vulgar show. A girl in pink dress with short skirts, galloped upon the stage, and sang in brazen soprano tones...she divulged the fact that she was attired in some half dozen skirts. It was patent that any one of them would have proved adequate for the purpose for which skirts were intended. An occasional man bent forward, intent upon the pink stockings. In such a show, Maggie did not realize it was a low place with frivolous show. She told Pete it was so great and wondered at the splendor of the costume and lost herself in calculations of the cost of the silks and laces (Vincent, 1993). Naturally, she was keen to the city entertainment life, and she wanted to live a life with much money, but her shadow or her instinct did not make a correct judgment on the temptation of such life. Eventually, her desire ruined her.

\section{The Influence of Animus on Maggie}

Anima and animus always reflect to the opposite sex and decide the quality of the gender relations. It should be known that everyone is born with certain features of the opposite sex biologically and psychologically. For thousands of years, female form their animus by contacting with the male. Both male and female gain the features of the opposite sex which guarantees the coordination and understanding between the sexes. It should be allowed to develop the male character in female or the female character in male. The opposite sex factor always remains in the unconsciousness. People with manhood on the surface may be quite weak and tender in the heart, but people with womanhood on the surface may be proud and headstrong unconsciously. According to Jung, animus will influence what kind of man a woman will choose. On this aspect, the animus of Maggie influenced her fate. She loved Pete at the first sight, that is to say, Pete must have the same feature as her animus, and Pete was quite complementary with the persona of Maggie. For Maggie the soft girl, Pete was a man with persona superiority and had certainly seen everything; and as he became aware that she was listening to him closely, he grew still more eloquent in his descriptions of his various happenings in his career. All these features which existed in Maggie's unconsciousness were what Maggie looked forward to, and it made her admire him deeply. It was Maggie's Animus that leads her to choose Pete as a lover or she would not fall to the prostitution.

\section{CONCLUSION}

From the above analysis, we can conclude that personality is one reason for Maggie's tragedy. She wanted to pursue a happy life, but she could not find a good way to gain it. She hoped that her boyfriend would bring good luck to her, but she could not see through the real nature of him and thus led to her tragic end. As a woman, she should control her fate by herself and do not depend on others. Only in this way can happy life come to a woman like Maggie.

\section{REFERENCES}

[1] Fryer, J. (1976). The Faces of Eve: Women in the Nineteenth Century American Novel. New York: Oxford UP.

[2] James N. (1983). Stephen Crane and Literary Impressionism. Pennsylvania: The Pennsylvania State University Press.

[3] Stephen C. (1986). Maggie: A girl of the Streets and Other Short Fiction. New York: Batam Books.

[4] Vincent Starrett. (1993). Maggie and Other Stories. New York: Modern Library.

[5] Jung. (2003). Jung's Philosophy of Personality. Beijing: Jiuzhou Press. 
Jiang Zhu was born in Changchun, China in 1971. He received his M.A. degree in English from Changchun University of Science and Technology, China in 2003.

$\mathrm{He}$ is currently an associate professor in School of Foreign Languages, Changchun University of Science and Technology. His research field is English and American literature.

Lemeng Han was born in Changchun, China in 1982. She received her M.A. degree in English from Changchun University of Science and Technology, China in 2012.

She is currently a lecturer in Department of Common Foreign Language Teaching, Guanghua College of Changchun University. Her research field is English and American literature. 